\title{
Centennial, but still current
}

Centenário, mas ainda atual

\author{
Paulo Augusto Achucarro Silveira ${ }^{1}$, Jacyr Pasternak ${ }^{2}$
}

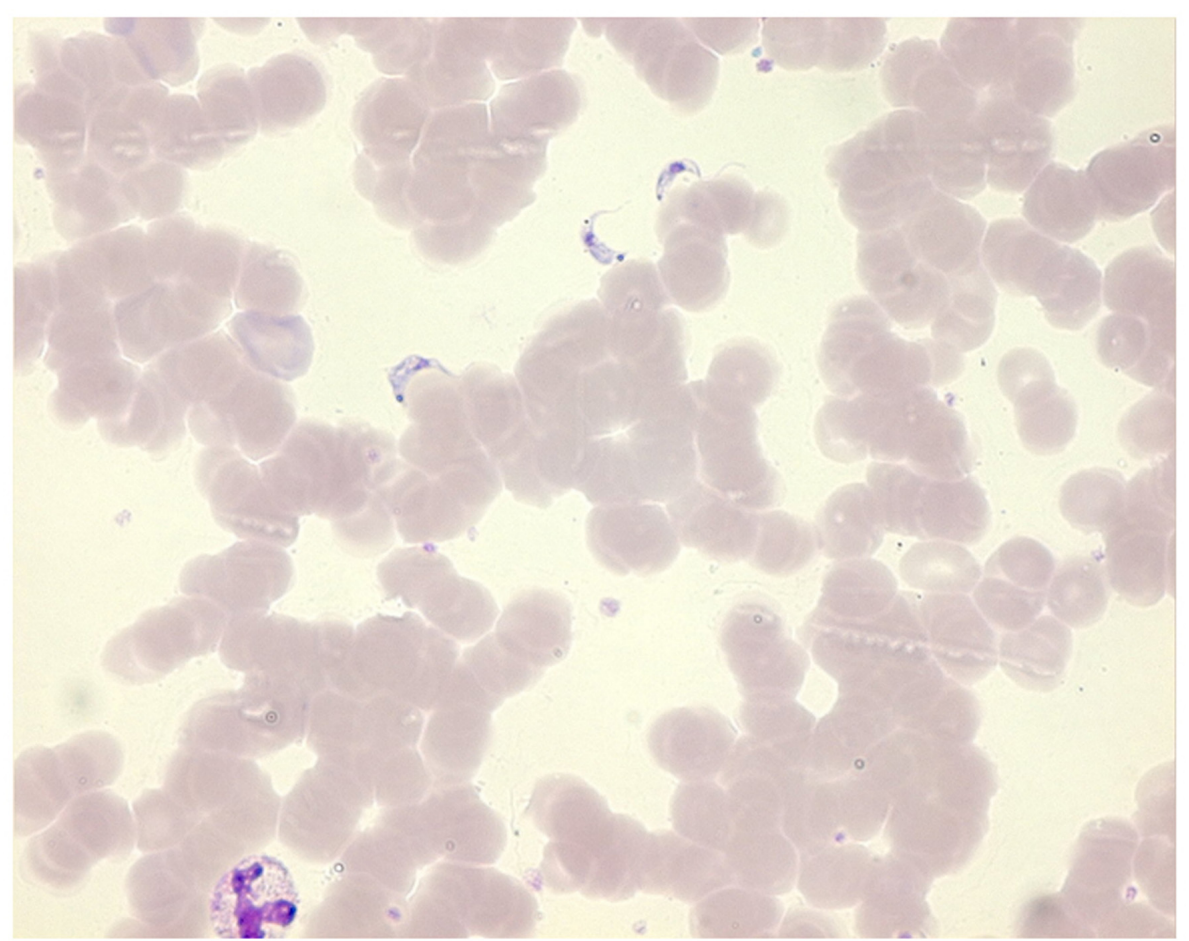

Figure 1. Trypanosoma cruzi in peripheral blood (Leishman x 1000)

In the centennial anniversary of the discovery of the etiologic agent of Chagas disease (Carlos Chagas discovered the disease, vector and etiologic agent all at once!), the subject is not only current, but the acute disease stills occurs. The vector-transmitted disease is already under control in Brazil, but the congenital and transfusional forms, and those by non-usual transmission, are still observed. Recently, an individual from the State of Santa Catarina went to the beach and drank garapa (sugar cane juice). The sugar cane was probably ground with triatomide and he developed severe acute myocarditis and acute Chagas disease. Similar cases were described in the State of Pará after ingestion of in natura açaí palm fruit pulp. The finding of Trypanosoma cruzi in peripheral blood confirmed the diagnosis (Figure 1).

\footnotetext{
'PhD in Hematology from Faculdade de Medicina da Universidade de São Paulo - USP, São Paulo (SP), Brazil.

${ }^{2} \mathrm{MD}$; Infectious disease Specialist; Head of the Nosocomial Infection Control Committee of Hospital Israelita Albert Einstein - HIAE, São Paulo (SP), Brazil.

Corresponding author: Paulo Augusto Achucarro Silveira - Avenida Albert Einstein, 627 - Morumbi - CEP 05651-901 - São Paulo (SP), Brazil - Tel.: 11 $3747-0450$ - e-mail: paasilveira@uol.com.br

Received on Feb 24, 2010 - Accepted on May 30, 2010
} 